\title{
Aerodynamic roughness length related to non-aggregated tillage ridges
}

\author{
M. Kardous ${ }^{1}$, G. Bergametti ${ }^{2}$, and B. Marticorena ${ }^{2}$ \\ ${ }^{1}$ Institut des Régions Arides - El Fjé, 4119 Médenine, Tunisie \\ ${ }^{2}$ Laboratoire Interuniversitaire des Systèmes Atmosphériques, UMR CNRS 7583, Universités Paris7-Paris12, CMC, 61 \\ avenue du Général de Gaulle, 94010 Créteil cedex, France
}

Received: 11 April 2005 - Revised: 18 August 2005 - Accepted: 9 September 2005 - Published: 30 November 2005

\begin{abstract}
Wind erosion in agricultural soils is dependent, in part, on the aerodynamic roughness length $\left(z_{0}\right)$ produced by tillage ridges. Although previous studies have related $z_{0}$ to ridge characteristics (ridge height $(R H)$ and spacing $(R S)$ ), these relationships have not been tested for tillage ridges observed in the North African agricultural fields. In these regions, due to climate and soil conditions, small plowing tools are largely used. Most of these tools produce non-aggregated and closely-spaced small ridges. Thus, experiments were conducted in a 7-m long wind tunnel to measure $z_{0}$ for 11 ridge types covering the range of geometric characteristics frequently observed in south Tunisia. Experimental results suggest that $R H^{2} / R S$ is the first order parameter controlling $z_{0}$. A strong relationship between $z_{0}$ and $R H^{2} / R S$ is proposed for a wide range of ridge characteristics.
\end{abstract}

Keywords. Atmospheric composition and structure (biosphere-atmosphere interactions) - Hydrology (drought; erosion and sedimentation)

\section{Introduction}

Wind erosion occurs mainly in arid and semi-arid regions. It is an interactive surface-atmosphere process based on the equilibrium between forces acting to maintain soil grains at the surface and those acting to move them. Soil grains are maintained at the surface, mainly by gravitational and electrostatic forces which are dependent on soil characteristics (texture, aggregate sizes, moisture, etc.) (Chepil, 1956; Chepil and Woodruff, 1963). On the other hand, energy required to move the grains is provided by the wind friction velocity $\left(u_{*}\right)$.

In neutral conditions, according to Monin (1973), $u_{*}$ can be derived from the wind velocity profile:

$u_{(z)}=\frac{u_{*}}{k} \ln \frac{z}{z_{0}}$,

Correspondence to: G. Bergametti

(bergametti@lisa.univ-paris12.fr) where

$u_{(z)}$ : average wind velocity at height $z$;

$k$ : Von Karman's constant (0.4);

$z_{0}$ : aerodynamic roughness length.

As a consequence, wind erosion begins when $u_{*}$ exceeds the minimum value required to counterbalance gravitational and electrostatic forces (Greeley and Iversen, 1985). This defines a "static" threshold friction velocity, $u_{* t}$ (Bagnold, 1941) which corresponds to the minimum $u_{*}$ required to initiate erosion. This $u_{* t}$ is mainly controlled by surface roughness and soil characteristics. Roughness elements (vegetation, clods, gravel, pebbles, etc.) absorb a part of the wind momentum needed to initiate particle motion. Thus, for a given soil, the erosion threshold is mainly controlled by the surface roughness, i.e. number, size, and shape of nonerodible elements present on the soil surface. Aerodynamic roughness length, $z_{0}$, can be used as an integrative parameter to describe the effects of surface roughness on the erosion threshold.

In cultivated areas, where conventional tillage is used, owing to the limited vegetation cover, tillage ridges and soil cloddiness are the only soil roughness elements that contribute to reduce wind erosion. Ridges raise $z_{0}$ (Fryrear, 1984; Hagen and Armbrust, 1992) and, therefore, increase $u_{* t}$. Armbrust et al. (1964) indicated that, for equal $u_{*}$, the presence of ridges could reduce total erosion up to $50 \% \mathrm{com}$ pared to unridged surfaces. Moreover, ridges contribute to reduced wind erosion by trapping saltating particles in furrow bottoms (Fryrear, 1984; Hagen and Armbrust, 1992). These studies suggest that, over agricultural lands, geometric characteristics of ridges govern the wind erosion susceptibility.

In semi-arid regions, limited rainfall and weak soil structure favor wind erosion. This problem is accentuated in some cultivated areas due to repeated surface soil disturbance by tillage tools. In most cases, tillage practices pulverize the soil and produce a flat, bare, and smooth surface which becomes more susceptible to wind erosion. In south Tunisia, the 


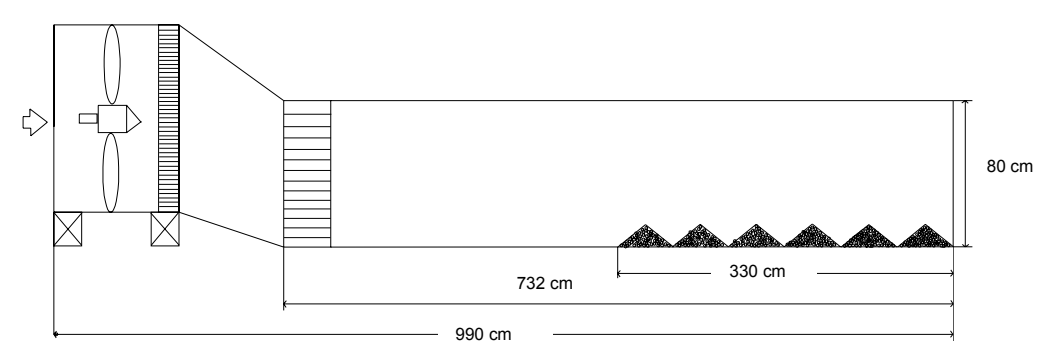

Fig. 1. Schematic view of the wind tunnel and location of the tested sample.

frequent use of disc plow has reinforced wind erosion which reaches $180 \mathrm{tha}^{-1}$ year ${ }^{-1}$ (Akrimi et al., 1993). Therefore, soil conservation practices are urgently needed to control wind erosion in agricultural soils of arid and semi-arid regions. Since $z_{0}$ strongly controls $u_{* t}$, the establishment of relations between geometric characteristics of ridge (ridges height $(R H)$ and ridge spacing $(R S))$ and $z_{0}$ would help to determine the frequency and intensity of the wind erosion events.

Aerodynamic roughness lengths produced by ridged surfaces have been experimentally studied in both wind tunnels and field conditions. Hagen and Armbrust (1992) performed wind tunnel experiments on armoured ridges ranging from 2.37 to $15 \mathrm{~cm}$ in height and 21.5 to $326.1 \mathrm{~cm}$ in spacing. Under field conditions, Saleh et al. (1997) measured $z_{0}$ for surfaces roughened with five different tillage implements: disc plow, moldbord plow, chisel and two types of lister. The resulting soil roughness was due to the ridges and the presence of medium to large aggregates at the soil surface. Measured $z_{0}$ values ranged from 0.16 to $4.22 \mathrm{~cm}$. Hagen and Armbrust (1992) and Saleh et al. (1997) proposed, respectively, Eqs. (2) and (3) to calculate $z_{0}$ based on $R H$ and $R S$ as follows:

$$
\frac{z_{0}}{R H}=\frac{1}{-64.1+135.5 \cdot \frac{R H}{R S}+\frac{20.84}{\sqrt{\frac{R H}{R S}}}}
$$

$z_{0}=0.0315 \cdot C_{r r}+1.289 \cdot C_{r r}^{2}+0.045 \cdot K_{r}^{0.61}$,

where

$C_{r r}$ : Random roughness (m);

$K_{r}$ : Ridge roughness factor $=4 R H^{2} / R S(\mathrm{~m})$. These relationships have been established for a limited range of ridge sizes: $R H / R S<0.21$ for Hagen and Armbrust (1992) and $R H / R S$ values $<0.3$ for Saleh et al. (1997). However, in cultivated areas of south Tunisia, due to the limited rainfall and the weak thickness of the soil layer, small plowing tools, relatively low in cost, are preferentially used. They produce ridges of limited height and closely spaced, with $R H / R S$ values of $0.2-$ 0.36 (Kardous, unpublished results).

The objectives of this study were (1) to develop an equation relating $z_{0}$ to the ridge characteristics observed in agricultural soils of semi-arid North Africa and, thus (2) extend the range of validity of the relationships previously established.

\section{Experimental procedure}

Experiments were carried out in two independent stages. First we investigated, in wind tunnel experiments, relationships between $z_{0}$ and geometric characteristics of ridges, and then we evaluated in situ the parameterization obtained in wind tunnel.

\subsection{Wind tunnel experiment}

A portable, push-type, non-recirculating wind tunnel, $7.32 \mathrm{~m}$ long with a rectangular cross section $0.6 \mathrm{~m}$ wide and $0.8 \mathrm{~m}$ high, was used to evaluate wind profile parameters over ridged bare surfaces. The wind-making equipment is composed of a gasoline engine and an axial type ventilating fan. Air velocity is changed by the speed of the engine. Airflow generated by a 6-blade fan was redistributed by turning vanes and series of screens in the transition section connecting the fan to the duct and an aluminum honeycomb-type air straightner located between the duct and the transition section (Fig. 1).

The experiment involved 11 sets of simulated ridges manually constructed using appropriate steel patterns. A sandy soil was used, composed of $30 \%$ aggregates greater than $1 \mathrm{~mm}$ and smaller than $30 \mathrm{~mm}$, and of $70 \%$ of loose material. Soil samples were taken from the top $10 \mathrm{~cm}$ from an agricultural field located $30 \mathrm{~km}$ to the southeast of Medenine (south Tunisia). Ridges were installed perpendicular to the airflow at about $3.3 \mathrm{~m}$ from the entrance of the tunnel working section. Before each experiment, a sufficient quantity of water was applied to the ridge surfaces to prevent wind erosion, which could induce an additional roughness due to saltating grains. This has led to a decrease in ridge height, which was measured after wetting. Ridge characteristics were chosen to be as representative as possible of ridges observed in agricultural fields of Tunisia: $R H$ and $R S$ values ranged from 5.7 to $10.9 \mathrm{~cm}$ and 16 to $40 \mathrm{~cm}$, respectively. The $R H / R S$ ratio varied from 0.18 to 0.38 .

In neutral conditions, the wind velocity profile in the inner boundary layer is described by a log-law (Eq. 1). For rough and undulating surfaces, such as ridged surfaces, the height from the ground, $z$, may not be appropriate to reference heights of wind velocities in the surface layer. A zero-plane displacement height, $D$, is then introduced in the equation of the vertical wind profile (Eq. 4) (Panofsky and 
Table 1. Selected parameters for the determination of the aerodynamic roughness length $\left(z_{0}\right)$ and the displacement height $(D)$ for various ridges characteristics (spacing: $R S$; height: $R H$ ).

\begin{tabular}{ccccccccccccccccccccccccc}
\hline \multicolumn{2}{c}{$R S=40$} & \multicolumn{2}{c}{$R S=27.6$} & \multicolumn{2}{c}{$R S=34.6$} & \multicolumn{2}{c}{$R S=34.5$} & \multicolumn{2}{c}{$R S=43$} & \multicolumn{2}{c}{$R S=34.3$} & \multicolumn{2}{c}{$R S=24$} & \multicolumn{2}{c}{$R S=28.6$} & \multicolumn{2}{c}{$R S=19.1$} & \multicolumn{2}{c}{$R S=24$} \\
\multicolumn{2}{c}{$R H=7.3$} & $R H=7.7$ & \multicolumn{2}{c}{$R H=9.6$} & \multicolumn{2}{c}{$R H=7.4$} & \multicolumn{2}{c}{$R H=9.6$} & \multicolumn{2}{c}{$R H=10.9$} & \multicolumn{2}{c}{$R H=7.3$} & \multicolumn{2}{c}{$R H=10.5$} & \multicolumn{2}{c}{$R H=7.3$} & \multicolumn{2}{c}{$R H=8.6$} & $R H=5.7$ \\
$z$ & $u$ & $z$ & $u$ & $z$ & $u$ & $z$ & $u$ & $z$ & $u$ & $z$ & $u$ & $z$ & $u$ & $z$ & $u$ & $z$ & $u$ & $z$ & $u$ & $z$ & $u$ \\
\hline 12 & 467 & 8 & 381 & 14 & 519 & 12 & 644 & 13 & 668 & 15 & 620 & 14 & 594 & 14 & 519 & 11 & 509 & 14 & 558 & 10 & 585 \\
14 & 549 & 9 & 395 & 15 & 594 & 15 & 713 & 15 & 742 & 17 & 691 & 15 & 660 & 16 & 585 & 13 & 594 & 16 & 636 & 12 & 660 \\
16 & 628 & 10 & 444 & 17 & 668 & 17 & 821 & 17 & 834 & 20 & 789 & 18 & 789 & 19 & 683 & 15 & 668 & 18 & 735 & 15 & 762 \\
20 & 720 & 11 & 489 & 20 & 713 & 21 & 888 & 21 & 905 & 23 & 894 & 22 & 858 & 22 & 782 & 17 & 755 & 21 & 821 & 17 & 834 \\
23 & 782 & 12 & 529 & 22 & 789 & 25 & 988 & 24 & 977 & 27 & 993 & 25 & 950 & 24 & 876 & 20 & 846 & 25 & 905 & 21 & 922 \\
29 & 858 & 15 & 620 & 25 & 828 & 30 & 1059 & 27 & 1044 & 31 & 1063 & 29 & 1029 & 28 & 956 & 24 & 934 & 28 & 998 & 24 & 988 \\
35 & 917 & 17 & 683 & 28 & 876 & - & - & 31 & 1092 & 35 & 1130 & 32 & 1078 & 31 & 1024 & 27 & 998 & 33 & 1078 & 28 & 1044 \\
- & - & 20 & 727 & 32 & 917 & - & - & 35 & 1134 & - & - & 37 & 1125 & 35 & 1083 & 32 & 1054 & 37 & 1139 & 32 & 1078 \\
- & - & 23 & 789 & - & - & - & - & 39 & 1175 & - & - & 42 & 1170 & 39 & 1130 & 36 & 1092 & 41 & 1184 & - & - \\
- & - & 26 & 834 & - & - & - & - & - & - & - & - & - & - & 43 & 1179 & - & - & - & - & - & - \\
- & - & 29 & 864 & - & - & - & - & - & - & - & - & - & - & - & - & - & - & - & - & - & - & - \\
- & - & 34 & 911 & - & - & - & - & - & - & - & - & - & - & - & - & - & - & - & - & - & - \\
\hline
\end{tabular}

$R S=$ Ridge Spacing $(\mathrm{cm}) ; R H=$ Ridge Height $(\mathrm{cm}) ; z=$ height of wind velocity measurements $(\mathrm{cm}) ; u=$ wind velocity $\left(\mathrm{cm} . \mathrm{s}^{-1}\right)$.

Dutton, 1984). Displacement height is linked to the mean level of total momentum absorption (Thom, 1971):

$u_{(z)}=\frac{u_{*}}{k} \ln \frac{z-D}{z_{0}}$,

Wind velocity was determined by measuring the air dynamic pressure using an alcohol manometer connected to a static Pitot tube. During each experiment, mean horizontal wind velocity was measured at least at seven heights from the furrow bottom (Table 1). Heights differed for each experiment due to the different ridge characteristics. The wind measurements were performed at least five minutes after changing the vertical position of the Pitot tube to ensure that the manometer was stable. Wind profile measurements were performed along the vertical center plane at the downwind end of the tunnel. Free stream wind velocities were greater than $10 \mathrm{~m} \mathrm{~s}^{-1}$ at $z=50 \mathrm{~cm}$.

Figure 2 provides an example of measured wind profile. Below $40 \mathrm{~cm}$, two different regions can be observed: one associated with the internal boundary layer and other, following a log profile, associated with the ridged surface. Above $40 \mathrm{~cm}$, flow tends to the free stream velocity. Measurements corresponding to the ridged surface (white points on Fig. 2) were selected to fit the log-profile and determine the $z_{0}$ and $D$ values induced by the ridges (Table 1 ).

\subsection{Field experiment}

To test the validity of wind tunnel results under natural conditions, an experiment was performed in spring 2000 in an agricultural field located in south Tunisia (Dar Dahoui experimental range, $33^{\circ} 17^{\prime} 41^{\prime \prime} \mathrm{N}$ and $\left.10^{\circ} 46^{\prime} 57^{\prime \prime} \mathrm{E}\right)$. The average annual precipitation for this area is lower than $200 \mathrm{~mm}$, and the soil is composed of fixed aeolian sand with very low amounts of fine particles and organic matter. The

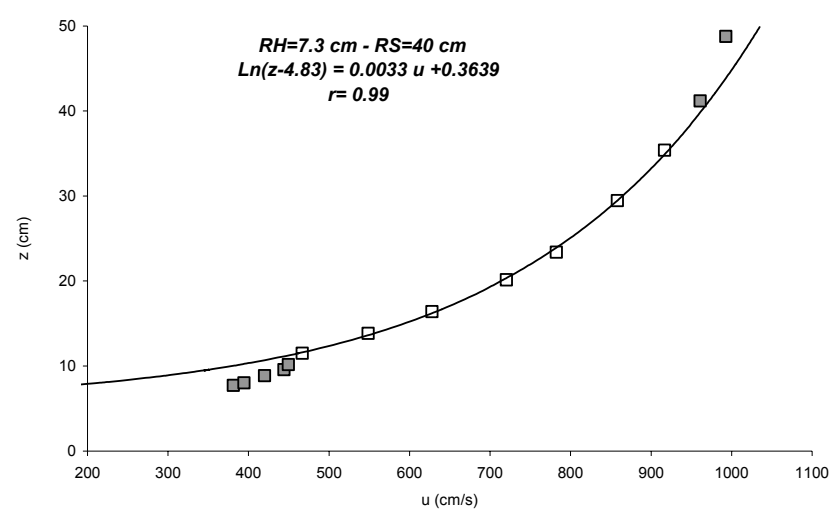

Fig. 2. Measured wind velocity profile (squares). Aerodynamic roughness length $\left(z_{0}\right)$ and the displacement height $(D)$ are determined by fitting on the log-law profile (Eq. 4, continuous line) only the wind velocity measurements corresponding to the white squares. ( $R H$, ridge height; $R S$, ridge spacing).

experimental field $(135 \times 135 \mathrm{~m})$ was moldboard plowed perpendicularly to the prevailing wind direction. The resulting surface is characterized by well marked ridges with a low amount $(30 \%)$ of small clods $(<30 \mathrm{~mm})$ and aggregates exposed on the surface and a wind erodible fraction representing about $70 \%$ of the soil.

\subsubsection{Geometric characteristics of ridges}

The geometric characteristics of the ridges were determined by using a laser profilograph (Boisson-PL1000). This instrument consists of a laser cell which can be displaced automatically in a $(\mathrm{X}, \mathrm{Y})$ plane to measure the height separating the cell to the soil surface over a 1-square meter area with a resolution of $0.5 \mathrm{~cm}$ in $\mathrm{X}$ and $4 \mathrm{~cm}$ in $\mathrm{Y}$. Precision of the 
Table 2. Heights for temperature (T) and wind (W) measurements.

\begin{tabular}{lccc}
\hline Temperature probe height $(\mathrm{m})$ & \multicolumn{2}{c}{ Anemometer height $(\mathrm{m})$} \\
\hline $\mathrm{T} 1$ & 0.455 & $\mathrm{~W} 1$ & 0.240 \\
$\mathrm{~T} 2$ & 1.445 & $\mathrm{~W} 2$ & 0.645 \\
$\mathrm{~T} 3$ & 1.815 & $\mathrm{~W} 3$ & 1.130 \\
$\mathrm{~T} 4$ & 3.660 & $\mathrm{~W} 4$ & 1.650 \\
& & W5 & 1.995 \\
& W6 & 2.350 \\
& W7 & 3.210 \\
& W8 & 3.980 \\
& & W9 & 4.480 \\
& & W10 & 5.090 \\
& W11 & 5.720 \\
& & W12 & 7.130 \\
\hline
\end{tabular}

instrument for the measurement of the distance to the soil surface is of the order of $1 \mathrm{~mm}$.

\subsubsection{Aerodynamic roughness length}

Wind velocity and air temperature profiles were measured using a 10-m telescopic mast, with instruments being fixed on 1-m booms placed so that instruments were not affected by the mast. Wind velocities were measured at $12 \mathrm{lev}-$ els, using conventional anemometers (A100R-Vector instruments $($ ) , and the wind direction was measured at an intermediate level (W200P-Vector instruments $®$ ). The consistency of measurements from all anemometers was checked in the field. Air temperatures were simultaneously measured at 4 levels using ventilated probes (ASPTC, Aspirated Shield With Fine Wire Thermocouple Type Chromel constantan, Campbell@). These probes allow one to determine the air temperature with a precision of $0.05^{\circ} \mathrm{C}$. Data acquisition of all dynamic parameters was performed with a data logger over three days, with a 5-s time step. The heights at which wind velocity measurements were performed and the number of anemometers to select were determined as a function of experimental conditions, mainly by fetch. Heights of measurements were spaced to be as close as possible to a logarithmic scale (Table 2).

Since $z_{0}$ values are expected to be low for this type of surface, determination of the levels of measurement must be as precise as possible. For the highest levels, heights were measured by reference to the top of the mast while a precise determination of the height relative to the ground was performed with a theodolite (Zeiss-Ni21) for the lowest levels (up to $\sim 2 \mathrm{~m}$ ). The mean ground level was obtained by averaging 28 measurements made within a surface of $75 \times 150 \mathrm{~cm}^{2}$ around the lowest anemometer. The sampling points were located in the intersection point of a square grid of about $25 \mathrm{~cm}$. Additional measurements of the relative distance between the instruments have been performed.

Within each day and during the three days of experimentation, the meteorological conditions were not constant,
Table 3. Aerodynamic roughness length $\left(z_{0}\right)$, displacement height $(D)$ and wind friction velocity $\left(u_{*}\right)$ for various ridge characteristics (spacing: $R S$; height: $R H$ ).

\begin{tabular}{ccccccc}
\hline $\mathrm{N}^{\circ}$ & $\begin{array}{c}R S \\
(\mathrm{~cm})\end{array}$ & $\begin{array}{c}R H \\
(\mathrm{~cm})\end{array}$ & $R H / R S$ & $\begin{array}{c}z_{0} \\
(\mathrm{~cm})\end{array}$ & $\begin{array}{c}D \\
(\mathrm{~cm})\end{array}$ & $\begin{array}{c}u_{*} \\
(\mathrm{~cm} . \mathrm{s}-1)\end{array}$ \\
\hline 1 & 40.0 & 7.3 & 0.18 & 1.44 & 4.83 & 121 \\
2 & 27.6 & 7.7 & 0.28 & 2.04 & 1.80 & 134 \\
3 & 34.6 & 9.6 & 0.28 & 2.97 & 3.81 & 157 \\
4 & 34.5 & 7.4 & 0.21 & 1.38 & 4.16 & 143 \\
5 & 43.0 & 9.6 & 0.22 & 2.09 & 1.96 & 166 \\
6 & 34.3 & 10.9 & 0.32 & 4.61 & 2.20 & 233 \\
7 & 24.0 & 7.3 & 0.30 & 2.65 & 3.45 & 179 \\
8 & 28.6 & 10.5 & 0.37 & 4.20 & 3.39 & 214 \\
9 & 19.1 & 7.3 & 0.38 & 2.39 & 3.13 & 170 \\
10 & 24.0 & 8.6 & 0.36 & 3.97 & 2.59 & 211 \\
11 & 16.0 & 5.7 & 0.36 & 1.58 & 2.02 & 147 \\
\hline
\end{tabular}

especially the wind direction and velocity. Therefore, pertinent data were selected using different criterions to allow for the reliable measures of $z_{0}$. The gradient method used for the inversion of dynamical parameters requires an averaging of wind velocity and temperature (Wieringa, 1993). In this experiment, we averaged over $15 \mathrm{~min}$. Following Karlsson (1986), the stability conditions have been defined as a function of the range of the Richardson number, but only data recorded for neutral conditions were selected for dynamical treatment. Moreover, inversion of dynamical parameters was performed only if the wind direction was facing the instruments, with a range of variation of $\pm 90^{\circ}$ to eliminate situations for which the experimental device could induce perturbation of measurements and to select situations for which the wind direction was perpendicular to ridges. The computation was performed only if a minimum value of $1 \mathrm{~m} \mathrm{~s}^{-1}$ was measured by all the anemometers.

To increase the reliability of results from this numerical retrieval, additional criteria on retrieved parameters have been used. From a numerical point of view, the fitting has been considered as relevant if (1) average deviation between measured and fitted wind velocities $\left(u_{m}\left(z_{i}\right)-u_{f}\left(z_{i}\right)\right)$ is lower than $5 \%$, and (2) average deviation between measured and fitted temperature gradients $\left(\Delta \theta_{m}\left(z_{i}\right)-\Delta \theta_{f}\left(z_{i}\right)\right)$ is lower than $0.05^{\circ}$. To discriminate between cases of free convection, profiles for $u_{*}<0.1 \mathrm{~m} \mathrm{~s}^{-1}$ were rejected. After these different procedures were applied, we obtained 8 profiles. A fitting of the average measured wind velocities and air temperature, using the classical equations of the Monin-Obukhov (1954), allows one to determine the dynamical parameters $u_{*}, \theta^{*}$ and $z_{0}$. We used the software procedure optimized by Frangi and Richard (2000). 


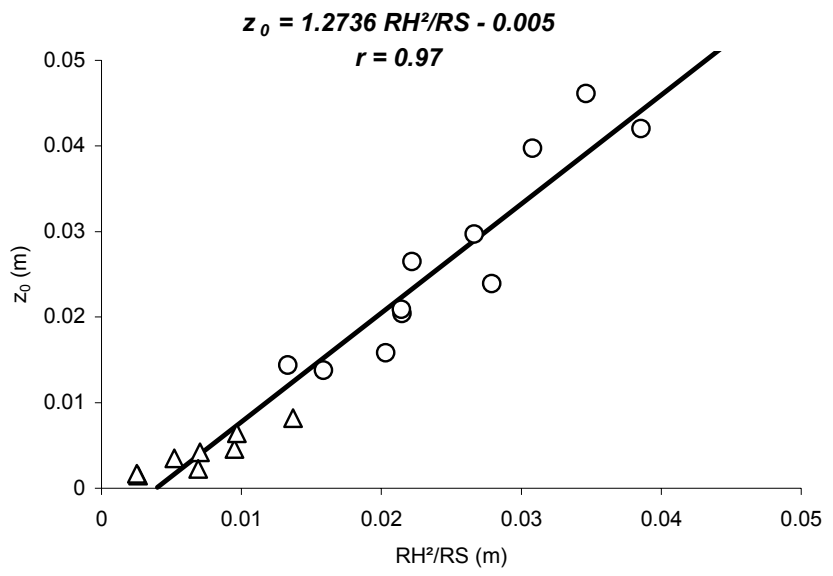

Fig. 3. Aerodynamic roughness length $\left(z_{0}\right)$ as a function of $R H^{2} / R S$ $(R H$, ridge height; $R S$, ridge spacing). Circles: this study; triangles: Hagen and Armbrust (1992).

\section{Results and discussion}

3.1 Parameterization of aerodynamic roughness length from wind-tunnel experiments

Measured wind profiles were used to determine $z_{0}, D$, and $u_{*}$ (Table 3 ). An iterative procedure (IP), by minimizing the difference between measured and computed wind velocities, was used to fit the wind profile using Eq. (4). Depending on the data set, from 6 to 12 wind velocity measurements were located in the log-law region and were used to fit wind profiles. An example of a fitted wind profile is given in Fig. 2. Using this procedure, $z_{0}$ and $D$ values ranged between 1.38 and $4.61 \mathrm{~cm}$, and 1.80 and $4.83 \mathrm{~cm}$, respectively.

However, the estimation of both $z_{0}$ and $D$ from the log-wind profile could be questionable and could result in some scatter of results. To check the $z_{0}$ estimation, we also computed $z_{0}$ from $D$ values provided by Wossenu et al. (1989), who proposed $D / R H=0.5$ for ridges similar to ours, i.e. with a touching base and a triangular shape. The $z_{0}$ values obtained from both methods were highly correlated $\left(z_{0(I P)}=1.24 z_{0(D=0.5 R H)}+0.1 ; r=0.87 ; P<0.01\right)$, with $z_{0}$ being expressed in $\mathrm{cm}$. This result shows the consistency of the method used, which suggests that $z_{0}$ can be retrieved with an uncertainty of the order of $25 \%$, depending on the method used for the retrieval.

Following the dependence of $z_{0}$ on $R H^{2} / R S$ observed by Hagen and Armbrust (1992) and, later, by Saleh et al. (1997), Fig. 3 shows the good relationship $(r=0.97 ; P<0.001)$ obtained from our data and from those by Hagen and Armbrust (1992). This result suggests that $z_{0}$ of a tilled surface (in m) can be estimated from the geometric characteristics of ridges (in $\mathrm{m}$ ) using the following relation:

$$
z_{0}=1.27 \cdot \frac{R H^{2}}{R S}-0.005,
$$

Although a strong relationship was also found between $z_{0}$ and $R H^{2} / R S$ from the data by Saleh et al. (1997) (Fig. 4), the

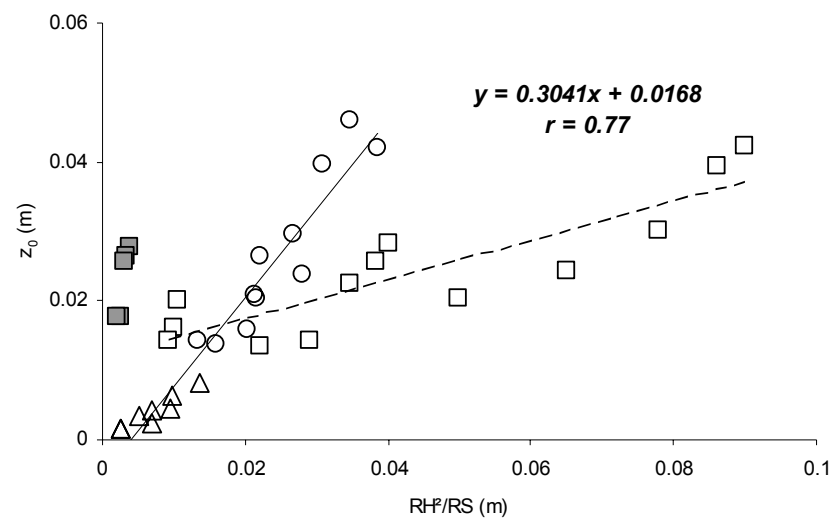

Fig. 4. Aerodynamic roughness length $\left(z_{0}\right)$ as a function of $R H^{2} / R S$ ( $R H$, ridge height; $R S$, ridge spacing). Circles: this study; triangles: Hagen and Armbrust (1992); squares: Saleh et al. (1997). The solid line represents the relation for ridges with a little random roughness and the dashed line represents ridges with random roughness caused by clods. $R H^{2} / R S$ ratios for data from Saleh et al. (1997) have been corrected to account for the rotation coefficient when ridges were not perpendicular to the wind direction. Note that the relationship from data by Saleh et al. (1997) does not account for the grey squares which correspond to the moldboard plow.

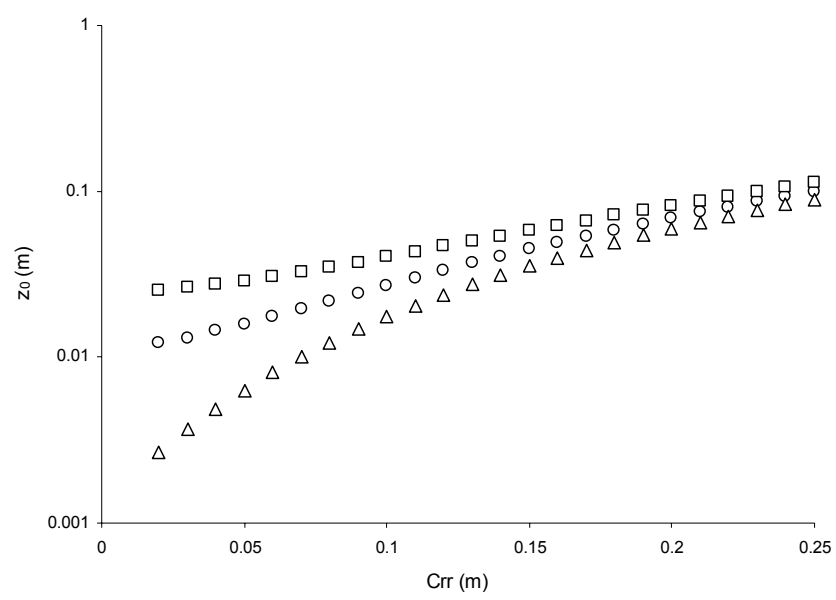

Fig. 5. Aerodynamic roughness length $\left(z_{0}\right)$ as a function of the random roughness $\left(C_{r r}\right)$, from Eq. (3). Circles, squares and triangles correspond to $R H^{2} / R S=0.09,0.025$ and $0.001 \mathrm{~m}$, respectively.

slope of the regression differed significantly from that of the Eq. (5).

Among the various hypotheses that can be proposed to explain such a difference, the orientation of ridges does not appear as a key factor. Indeed, the difference between $z_{0}$ measured by Saleh et al. (1997) and those obtained from Eq. (5), is of the same magnitude for perpendicular oriented ridges. When the $R H^{2} / R S$ ratios are corrected to account for the rotation coefficient for directions different from perpendicular, the $z_{0}$ measured by Saleh et al. (1997) remain strongly lower than those obtained in this study or by Hagen and Armbrust (1992). 


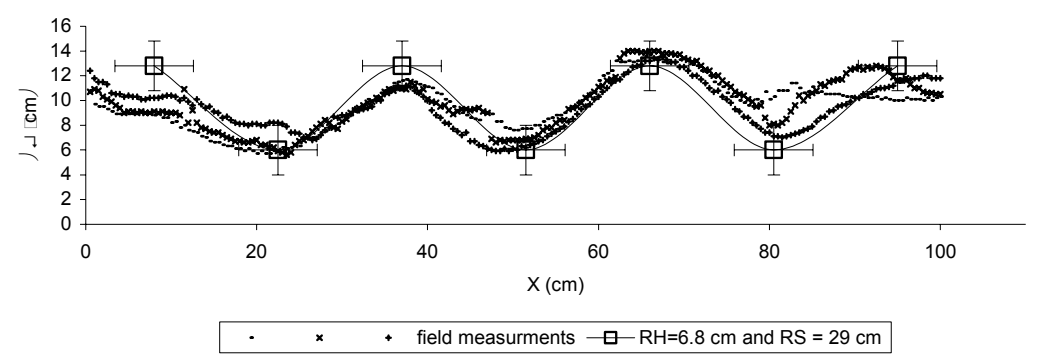

Fig. 6. Laser profilograph measurements of ridge characteristics $(R H$, ridge height; $R S$, ridge spacing) at the experimental field.

Table 4. Measured characteristics of ridges (spacing: $R S$; height: $R H)$ at the experimental agricultural field using laser profilograph.

\begin{tabular}{cccccccc}
\hline & $R S(\mathrm{~cm})$ & \multicolumn{3}{c}{$R H(\mathrm{~cm})$} & \multicolumn{3}{c}{$R H^{2} / R S(\mathrm{~cm})$} \\
\hline $\mathrm{n}$ & Mean & Std & $\mathrm{n}$ & Mean & Std & $R H^{2} / R S$ & Std \\
337 & 29.0 & 4.6 & 415 & 6.8 & 2.0 & 1.59 & 1.19 \\
\hline
\end{tabular}

Large-size aggregates, as those produced by the tillage tools used by Saleh et al. (1997), could significantly affect the surface roughness. Saleh et al. (1997) proposed an expression which allows one to estimate $z_{0}$ from a weighted function of both random roughness, $C_{r r}$, produced by largesize aggregates and a roughness due to the geometric characteristic of ridges, $K_{r}$, which is equal to $4 R H^{2} / R S$ (Eq. 3). The effect of random roughness on $z_{0}$ increases with $C_{r r}$. Indeed, when $C_{r r}$ is high, $z_{0}$ is similar in value to $R H^{2} / R S$ (Fig. 5). Considering the data set collected by Saleh et al. (1997), $C_{r r}$ terms contribute at least $35 \%$ and up to $90 \%$ in the $z_{0}$ computed by Eq. (3). As a consequence, these data cannot be considered as representative of the effect of ridge characteristics on aerodynamic roughness length, but rather of a joint effect of both random and ridge roughness.

Surprisingly, roughness of ridges having large or medium size aggregates appears to be lower than that of ridges having the same $R H^{2} / R S$, but without significant random roughness (Fig. 4). This could suggest that the "additional" random roughness has a "smoothing" effect on ridges. Complementary experiments are required to confirm this finding.

\subsection{Comparison with in-situ measurements}

Figure 6 shows laser profilograph measurements of geometric ridge characteristics at the experimental field. Mean values of $R S$ and $R H$ obtained by this method were 29 and $6.8 \mathrm{~cm}$, respectively, leading to a mean $R H^{2} / R S$ ratio of $1.59 \mathrm{~cm}$ (Table 4). We should note that the dispersion of values is greater for $R H^{2} / R S(\mathrm{CV}=75 \%)$ than for $R S(\mathrm{CV}=16 \%)$ or $R H(\mathrm{CV}=29 \%)$.

Aerodynamic roughness length was determined from the analysis of wind profile measurements performed in situ. Results give a $z_{0}$ value of $2.78 \mathrm{~cm}$, with a standard deviation of $1.18 \mathrm{~cm}$. Although this value is within the range of the $z_{0}$ measured in the wind tunnel $(1.4-4.6 \mathrm{~cm})$, it is nearly 1.8 times that predicted by Eq. (5) $\left(z_{0}=1.53 \mathrm{~cm}\right)$.

Despite large uncertainty in the measurement of the $R H^{2} / R S$ ratio $(75 \%)$, this result shows a satisfying consistency, suggesting that Eq. (5) could be used to predict, with an acceptable precision, $z_{0}$ over tilled surfaces (until the $R H^{2} / R S$ ratio can be precisely assessed). Unfortunately, this tentative validation of Eq. (5) for agricultural fields concerns a parcel with geometric characteristics of ridges that have a low $R H^{2} / R S$ ratio. Such an experience should be repeated, especially over an agricultural parcel having higher ridges with less space in between.

\section{Summary and conclusions}

Existing relationships between $z_{0}$ and geometric characteristics of tilled ridges have been established for a limited range of ridge sizes $(R H / R S<0.2)$. This range is not well adapted to roughness resulting from ridges observed in agricultural soils of semi-arid North Africa, where small plowing tools, producing ridges of limited height and closely spaced, $(R H / R S>0.2)$ are used.

Wind tunnel experiments, involving 11 sets of simulated ridges, were conducted to determine the relationship between $z_{0}$ and geometric characteristics of tilled ridges. Ridge sizes were selected to be as similar as possible to those observed in agricultural fields of south Tunisia $(R H / R S=0.18-0.38)$.

In agreement with previous studies, our results show that $z_{0}$ mainly depends on $R H^{2} / R S$. A strong linear relation between $z_{0}$ and $R H^{2} / R S$ was obtained from our data and from those obtained by Hagen and Armbrust (1992) under similar conditions (wind tunnel, ridges perpendicular to wind direction, no significant amount of large size aggregates) but for smaller $R H^{2} / R S$. Experimental conditions of this study and that of Hagen and Armbrust (1992) cover a wide range of $R H / R S$, therefore, this relationship provides estimates of $z_{0}$ from a broad variety of ridge characteristics.

To validate Eq. (5) under field conditions, geometric characteristics of ridges of a tilled soil were measured with a laser profilograph (being $R H^{2} / R S=1.59 \mathrm{~cm}$ ) and $z_{0}$ was determined from wind velocity and temperature profiles measured during neutral conditions. Taking into account the various uncertainties, and even if additional field measurements will be necessary, the measured $z_{0}(2.78 \mathrm{~cm})$ 
compared satisfactorily with the value computed from Eq. (5) $(1.53 \mathrm{~cm})$. Thus, this result suggests that Eq. (5) could be used to estimate $z_{0}$ induced by tilled surfaces when the geometric characteristics of the ridges are known. From a practical point of view, the proposed relation could be useful in designing and recommending tillage tools that reduce the soil susceptibility to wind erosion in semi-arid regions.

Acknowledgements. Topical Editor F. D'Andréa thanks G. Cautenet and V. Lopez for their help in evaluating this paper.

\section{References}

Akrimi, N., Kardous, M., and Taamallah, H.: Mouvements de sable en relation avec la nature et la vitesse de certains outils de travail du sol en zones arides: étude d'un cas pratique, Revue des Régions Arides, 5, 35-57, 1993.

Armbrust, D. V., Chepil, W. S., and Siddoway, F. H: Effects of ridges on erosion of soil by wind, Soil Sci. Soc. Am. Proc., 28, 557-560, 1964.

Bagnold, R. A.: The physics of blow sand and desert dunes, Methuen, London, 265 pp., 1941.

Chepil, W. S. and Woodruff, N. P.: The physics of wind erosion and its control, Advances in Agronomy, 15, 211-302, 1963.

Chepil, W. S.,: Influence of moisture on erodibility of soil by wind, Soil Sci. Soc. Am. Proc., 20, 288-292, 1956.

Frangi, J. P. and Richard, D. C.: The WELSONS experiment: overview and presentation of first results on the surface atmospheric boundary-layer in semiarid Spain, Ann. Geophys., 18, 365-384, 2000,

SRef-ID: 1432-0576/ag/2000-18-365.
Fryrear, D. W.: Soil ridge-clods and wind erosion, Trans. ASAE, 27, 445-448, 1984.

Greeley, R. and Iversen, J. D.: Wind as a geological process on Earth, Mars, Venus and Titan, Cambridge University Press, Cambridge, 333 pp., 1985.

Hagen L. J. and Armbrust, D. V.: Aerodynamic roughness and saltation trapping efficiency of tillage ridges, Trans. ASAE, 35, 11791184, 1992.

Karlsson, S.: The applicability of wind profile formulas to an urbanrural interface site, Boundary Layer Meteorol., 34, 333-355, 1986.

Monin, A. S.: Boundary layers in planetary atmospheres, in: Dynamic Meteorology, edited by: Morel, P., D. Reidel Publishing Company, Boston, 419-458, 1973.

Monin, A. S. and Obukhov, A. M.: Basic turbulent mixing laws in the atmospheric surface layer, Trans. Akad. Nauk SSSR. Geofiz. Inst., 151, 163-187, 1954.

Panofsky, H. A. and Dutton, J. A.: Atmospheric turbulence: Models and methods for engineering applications, Wiley and Sons, New York, 397 pp., 1984.

Saleh, A., Fryrear, D. W., and Bilbro, J. D.: Aerodynamic roughness prediction from soil surface roughness measurement, Soil Sci., 162, 205-210, 1997.

Thom, A. S.: Momentum absorption by vegetation, Quart. J. Roy. Meteorol. Soc., 97, 414-428, 1971.

Wieringa, J.: Representative roughness parameters for homogeneous terrains, Boundary Layer Meteorol., 63, 323-363, 1993.

Wossenu, A., Gregory, J. M., and Borelli, J.: Wind profile: estimation of displacement height and aerodynamic roughness, Trans. ASAE, 32, 521-527, 1989. 